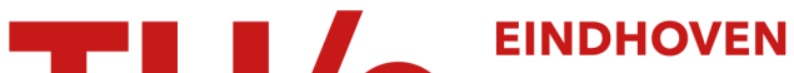 UNIVERSITY OF TECHNOLOGY
}

\section{A top-down approach to fabrication of high quality vertical heterostructure nanowire arrays}

Citation for published version (APA):

Wang, H., Sun, M., Ding, K., Hill, M. T., \& Ning, C. Z. (2011). A top-down approach to fabrication of high quality vertical heterostructure nanowire arrays. Nano Letters, 11(4), 1646-1650. https://doi.org/10.1021/nl2001132

DOI:

$10.1021 / \mathrm{nl} 2001132$

Document status and date:

Published: 01/01/2011

Document Version:

Accepted manuscript including changes made at the peer-review stage

Please check the document version of this publication:

- A submitted manuscript is the version of the article upon submission and before peer-review. There can be important differences between the submitted version and the official published version of record. People interested in the research are advised to contact the author for the final version of the publication, or visit the $\mathrm{DOI}$ to the publisher's website.

- The final author version and the galley proof are versions of the publication after peer review.

- The final published version features the final layout of the paper including the volume, issue and page numbers.

Link to publication

\section{General rights}

Copyright and moral rights for the publications made accessible in the public portal are retained by the authors and/or other copyright owners and it is a condition of accessing publications that users recognise and abide by the legal requirements associated with these rights.

- Users may download and print one copy of any publication from the public portal for the purpose of private study or research.

- You may not further distribute the material or use it for any profit-making activity or commercial gain

- You may freely distribute the URL identifying the publication in the public portal.

If the publication is distributed under the terms of Article $25 \mathrm{fa}$ of the Dutch Copyright Act, indicated by the "Taverne" license above, please follow below link for the End User Agreement:

www.tue.nl/taverne

Take down policy

If you believe that this document breaches copyright please contact us at:

openaccess@tue.nl

providing details and we will investigate your claim. 


\title{
A Top-down Approach to Fabrication of High Quality Vertical Heterostructure Nanowire Arrays
}

\author{
Hua Wang, ${ }^{\dagger}$ Minghua Sun, ${ }^{\dagger}$ Kang Ding, ${ }^{\dagger}$ Martin T. Hill, ${ }^{\ddagger}$ and Cun-Zheng Ning, ${ }^{*}$ \\ ${ }^{\dagger}$ School of Electrical, Computer, and Energy Engineering, Arizona State University, Tempe, Arizona, United States \\ ${ }^{\ddagger}$ COBRA Research Institute, Eindhoven University of Technology, Eindhoven, The Netherlands \\ Supporting Information
}

\begin{abstract}
We demonstrate a novel top-down approach for fabricating nanowires with unprecedented complexity and optical quality by taking advantage of a nanoscale self-masking effect. We realized vertical arrays of nanowires of $20-40 \mathrm{~nm}$ in diameter with 16 segments of complex longitudinal InGaAsP/InP structures. The unprecedented high quality of etched wires is evidenced by the narrowest photoluminescence linewidth ever produced in similar wavelengths, indistinguishable from that of the corresponding wafer. This top-down, maskfree, large scale approach is compatible with the established device fabrication processes and could serve as an important alternative to the bottom-up approach, significantly expanding ranges and varieties of applications of nanowire technology.
\end{abstract}

KEYWORDS: Reactive ion etching, photoluminescence linewidth, semiconductor nanowires, longitudinal heterostructure, top-down fabrication, self-masking

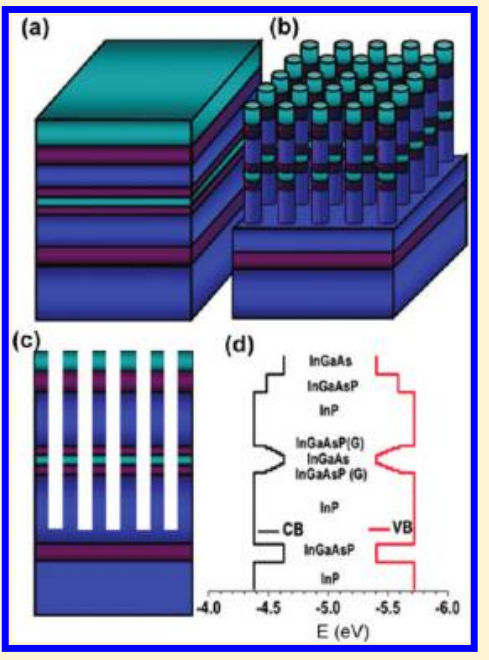

Cemiconductor nanowires have attracted much attention due $\checkmark$ to their unique electrical and optical properties, ${ }^{1-3}$ and the related applications in nanoelectronics, ${ }^{4}$ nanophotonics, ${ }^{5-7}$ and nanogenerators. ${ }^{8}$ Controlled fabrication of nanowires with desired longitudinal or axial structures is critical to integrating nanowires into various application platforms. ${ }^{9-12}$ Despite great success of bottom-up approach, control of longitudinal structures and doping profile remains challenging and far behind maturity levels of corresponding planar heterostructures; whereas topdown approaches have so far been unable to produce complex nanopillar structures down to true nanoscale with high surface quality. Among various bottom-up approaches used to grow nanowires, most of them are based on vapor-liquid-solid (VLS) mechanism ${ }^{2}$ using chemical vapor deposition (CVD), metalorganic chemical vapor deposition (MOCVD), ${ }^{10}$ molecular beam epitaxy (MBE), ${ }^{13}$ or laser-assisted catalytic growth. ${ }^{14}$ Since the early days of nanowires, great progress has been achieved in the creation of complex radial structures in the nanowires such as core- shell $^{7}$ and the longitudinal heterostructures. ${ }^{3,15}$ Even though the bottom-up approaches will continue to play an important role in the creation of various nanowires, there are critical issues that have not been or could not be readily addressed by the bottom-up approaches. ${ }^{16}$ Chief among them are (1) longitudinal control of structures and doping profiles, which are currently limited to simple heterointerfaces and single $\mathrm{p}-\mathrm{n}$ junctions; (2) poor surface states control which result in a wide PL spectrum (typically much wider than for the corresponding bulk materials) and thus poor light emission efficiency; and (3) the requirement of metal as catalysts to initiate wire growth, an approach that could lead to metal contamination, incompatibility with standard microfabrication. ${ }^{17,18}$ While top-down etching techniques have been used for fabricating much larger devices for a long time with complex vertical structures, but it has been infeasible to etch structures down to nanoscale with high quality.

In this paper, we describe an easy and large scale fabrication method using inductively coupled plasma reactive ion etching (ICP-RIE) from MOCVD grown wafer which has complex longitudinal structures and doping profiles built in during the MOCVD growth of the wafer. We demonstrate this approach by realizing InP and InGaAsP/InP nanowires etched from the respective wafers. The etched nanowires showed high crystal quality and with the PL almost indistinguishable from those of the corresponding wafers, indicating high surface quality of the etched wires. Etched from the epitaxial heterostructures, the nanowires can incorporate very complex compositional structure with highly controlled doping profile, such as p-i-n structure with composition graded sections, along the length. The method demonstrated in this paper combines the advantages of the well developed heterostructure growth technology with advanced

Received: January 11, 2011

Revised: $\quad$ March 6, 2011

Published: March 21, 2011 


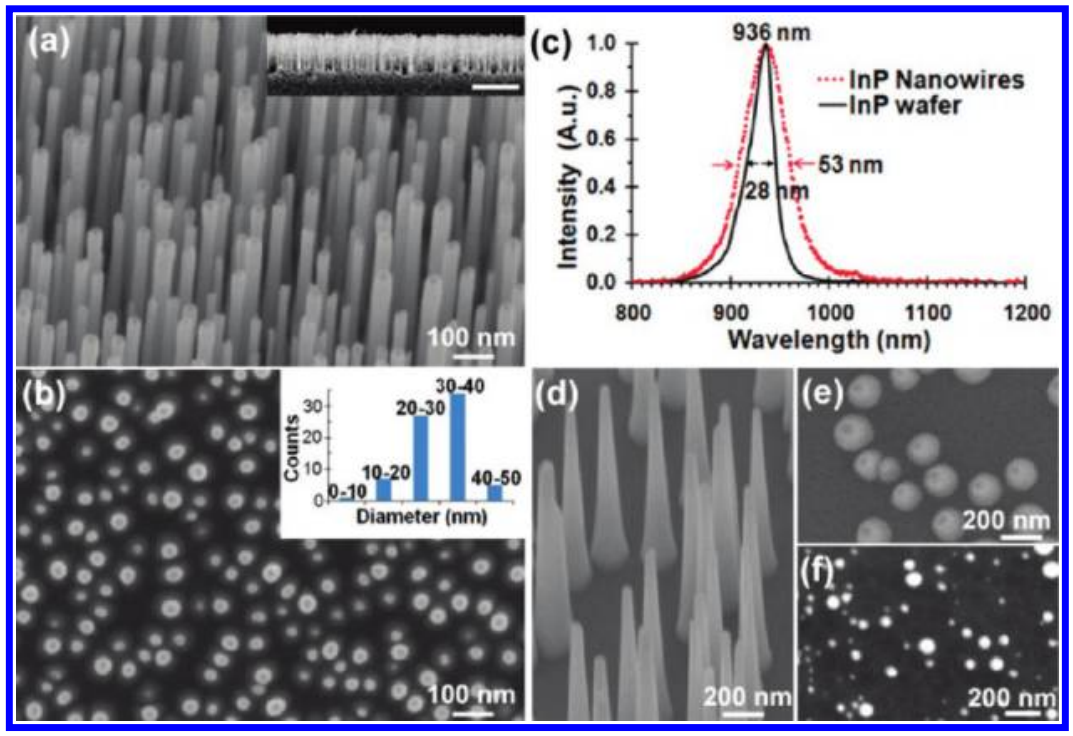

Figure 1. SEM images and PL spectrum of etched nanowires. (a) Tilted view SEM image of rod-shaped InP nanowires formed with $30 \mathrm{~W}$ platen power for $\mathrm{O}_{2}$ plasma treatment $(\mathrm{OPT})$; inset shows side view of the nanowire array (scale bar $\left.=1 \mu \mathrm{m}\right)$; (b) top view of nanowires shown in (a) with inset showing diameter distribution; (c) room-temperature PL spectra from rod-shaped InP nanowires and wafer; (d) tilted view of cone-shaped nanowires formed with $60 \mathrm{~W}$ platen power for OPT; (e) top view of the nanowires shown in (e); (f) top view of the nanowires formed with $40 \mathrm{~W}$ platen power for OPT.

ICP-RIE fabrication capability, assuring the vertical accuracy of the arbitrarily desired structures and the large scale manufacturability.

Two wafer samples were used for nanowire fabrication to demonstrate the powerfulness of the method. The first one is a commercial S-doped n-type InP (100) wafer (InPACT Inc., France), and the second wafer is a custom-designed epitaxial heterostructure grown by a commercial vendor (Landmark Technologies, Taiwan) on an InP (100) substrate. The nanowires were obtained from wafer pieces after etching in a Surface Technology Systems (STS) ICP-RIE system. An etching cycle consisted of one-minute of etching using a gas mixture of methane $\left(\mathrm{CH}_{4}\right)$ and hydrogen $\left(\mathrm{H}_{2}\right)$, followed by $10 \mathrm{~s}$ of $\mathrm{O}_{2}$ plasma treatment (OPT) carried out in the same ICP-RIE chamber. The cycle was repeated for tens of times in order to get desired length of the nanowires. During the $\mathrm{CH}_{4} / \mathrm{H}_{2}$ etching, coil power, which is the RF power supply inductively coupled to a coil electrode wrapping around the chamber wall, was set at $125 \mathrm{~W}$, while platen power, which is the other RF power supply inductively coupled to a platen electrode connecting to a sample chuck, was set at $75 \mathrm{~W}$. Both RF power supplies are operated at 13.56 MHz. $\mathrm{CH}_{4}$ and $\mathrm{H}_{2}$ were introduced into the chamber at 30 standard cubic centimeters per minute $(\mathrm{sccm})$ and $20 \mathrm{sccm}$ flow rate, respectively. The process pressure during the $\mathrm{CH}_{4} / \mathrm{H}_{2}$ etching was 15 mTorr. According to our experience of etching patterns defined by hard masks, the above condition gives the etched patterns smooth and vertical sidewalls. While the $\mathrm{CH}_{4} / \mathrm{H}_{2}$ etching was fixed at the optimal condition, the process parameters of $\mathrm{O}_{2}$ plasma treatment were varied to study the relation between the $\mathrm{O}_{2}$ plasma treatment and the formation of the nanowires. Unless mentioned otherwise, the $\mathrm{O}_{2}$ plasma recipe used in this study is as the following: the $\mathrm{O}_{2}$ flow rate was $49.5 \mathrm{sccm}$, the process pressure was $40 \mathrm{~m}$ Torr, and the coil power and platen power were 1000 and $30 \mathrm{~W}$, respectively.

Morphology and microstructure of the InP nanowires were observed using Hitachi S4700 field emission scanning electron microscopy (FESEM) and JEOL JEM 4000EX transmission electron microscopy (TEM). Cross-sectional sample preparation for SEM consisted of mechanical cutting and submerging the sample in liquid nitrogen before breaking. TEM sample was obtained by dispersing the nanowires on $\mathrm{Cu}$ grid. Chemical analysis of nanowires was performed using a FEI XL30 ESEM equipped with an energy-dispersive X-ray spectroscopy (EDS) detector.

Figure 1a shows an SEM image of the InP nanowires produced from the n-type InP wafer by ICP etching, taken at a tilt angle of $30^{\circ}$ with respect to the substrate surface. The rod-shaped nanowires were etched for 20 cycles in total. As can been seen, the individual nanowires were uniform in cross-section along their length. Central area of the round top ends was covered by some material showing dark contrast, which will be further elucidated in the EDX analysis described below. Seen from Figure 1a, the nanowires are too dense to expose their root ends, and those very small nanowires with diameter around $10 \mathrm{~nm}$ are obviously shorter than the other nanowires. The inset of Figure la shows the side view of the InP nanowires, which were relatively uniform in length, with an average length of $\sim 1 \mu \mathrm{m}$. The diameters of the nanowires ranged from 10 to $50 \mathrm{~nm}$, and mainly centralized from 20 to $40 \mathrm{~nm}$, as we can also see from the inset of Figure 1b. Shown in Figure 1b, the top view of the SEM image, all the nanowires appeared as bright round dots, implying an excellent vertical orientation of the nanowires, which is a unique advantage of the dry etching fabrication method. Measured from Figure 1b, a typical representative of the nanowires fabricated, the density of the nanowires is estimated to be around $1.8 \times 10^{10} \mathrm{~cm}^{-2}$, which is higher than that of nanowires fabricated by other methods. ${ }^{19}$

PL measurements were performed to verify the quality of InP nanowires using a near-infrared (NIR) micro-photoluminescence (PL) system. The nanowire samples were excited by a passively mode-locked Ti:sapphire laser (SpectraPhysics Tsunami, $790 \mathrm{~nm}, 150 \mathrm{fs}$ pulse duration, $80 \mathrm{MHz}$ repetition rate). 


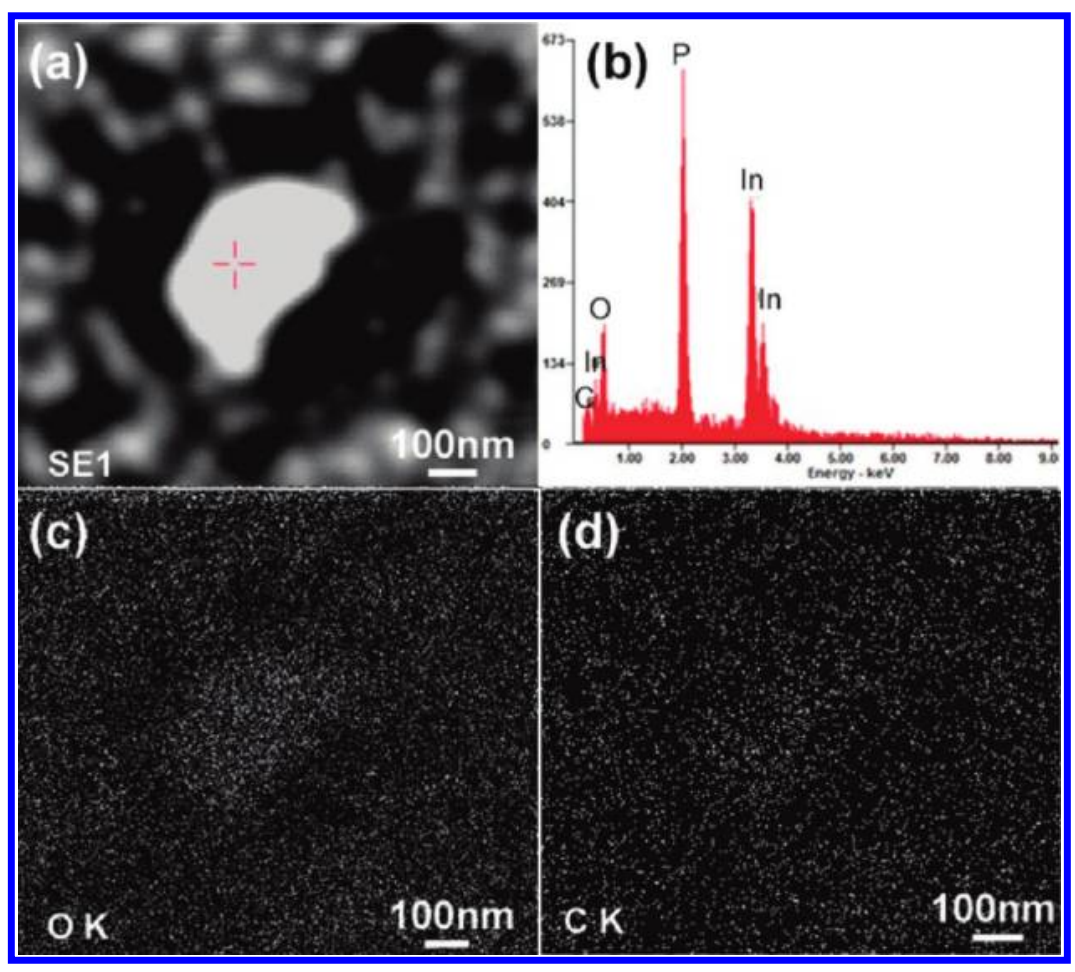

Figure 2. SEM-EDX identification and mapping of elements from nanowires. (a) SE image of mapping region. The bright spots represent top ends of InP nanowires, and the big bright spot in the central part is the top ends of a group of nanowires clustered together; (b) EDX peaks obtained from the top ends of the nanowires; (c) EDX mapping of element O illustrated oxygen was rich on the top ends of nanowires; (d) EDX mapping of element C illustrated that carbon was rich on the top ends of nanowires.

Focused by a long working distance lens, the laser beam was directed into the samples at some angle. Then the PL light emission was collected along the substrate normal direction by Mitutoyo objective lens $(50 \times)$. The signal was coupled to a monochromator with a 150 grooves $/ \mathrm{mm}$ grating and directed into liquid nitrogen cooled InGaAs array detectors. A vacuum cryostat with nitrogen cooling was utilized for low-temperature PL measurements. The InP nanowires are scratched and dispersed onto quartz substrate to avoid the signal of InP substrate.

Figure 1c shows the room temperature (RT) PL spectra of InP nanowires and compared with that of InP wafer. The PL peaks agree perfectly at $936 \mathrm{~nm}$, while the full width at half-maximum (FWHM) of the PL was $53 \mathrm{~nm}(75 \mathrm{meV})$ and $28 \mathrm{~nm}(40 \mathrm{meV})$ for the nanowires and the wafer, respectively. PL width is often a good measurement of optical quality of samples, with wider width indicating existence of surface states related to surface damages or surface roughness. Obviously there were surface damages caused by the etching process. Such surface states can be largely removed as we will show later for the case of InGaAsP nanowires. Even without additional treatment, the peak width of our etched nanowires was much smaller than that of other InP nanowires grown using bottom-up approaches at around $119,,^{20} 90,,^{21}$ and $84 \mathrm{meV},{ }^{19}$ indicating that our nanowires have much less surface state effects than those produced by bottom up approaches.

Figure $1 \mathrm{~d}$,e shows nanowires formed when the platen power for the $\mathrm{O}_{2}$ plasma treatment (OPT) was increased to $60 \mathrm{~W}$, while other process parameters during etching and $\mathrm{O}_{2}$ plasma treatment were kept the same as those to form nanowires in Figure 1a,b. As shown in Figure 1d,e, the nanowires had a cone shape, and the diameters of the bottom and the top ends of the nanowires were around $150 \mathrm{~nm}$ and tens of nanometers, respectively. The density of the nanowires was sparser than that of nanowires formed with $30 \mathrm{~W}$ OPT platen power (Figure 1a,b). Figure 1f shows a top-view SEM image of the nanowires formed when the OPT platen power was set at $40 \mathrm{~W}$. As shown in Figure $1 d-f$, the platen power for the $\mathrm{O}_{2}$ plasma treatment affects the formation and morphology of the nanowires and can be used as a control parameter for process optimization. And when the OPT platen power is large enough (e.g., $75 \mathrm{~W}$ ), no nanowires were formed, leaving very smooth and clean InP substrate surface. On the basis of our study, some dependence of size, shape, and length on the process parameters was found. The length of the nanowires could be changed from a few hundred nanometers to a couple of micrometers with different etching times. Among the OPT process parameters, platen power had direct influence on the size and shape of the nanowires. Other OPT process parameters, such as coil power and process pressure, did not change the size and shape significantly, while they may have indirect effects through platen power to change the density of the nanowires. We also found that keeping the process parameters for etching at optimal condition was critical to obtain nanowires with good quality. The more direct and quantitative control of morphology of the nanowires such as diameter, height, shape, and density is under further systematic investigation.

It is important to note that there were no masks intentionally fabricated on the InP substrate before etching. Therefore the formation of the nanowires is a result of a nanoscale self-masking phenomenon and deserves careful analysis. Similar "grassy" phenomena were usually treated as an unwanted side effect, ${ }^{22}$ and only recently similar grass structures on silicon have been studied for enhanced optical absorption. ${ }^{23} \mathrm{InP}$ grass structures 


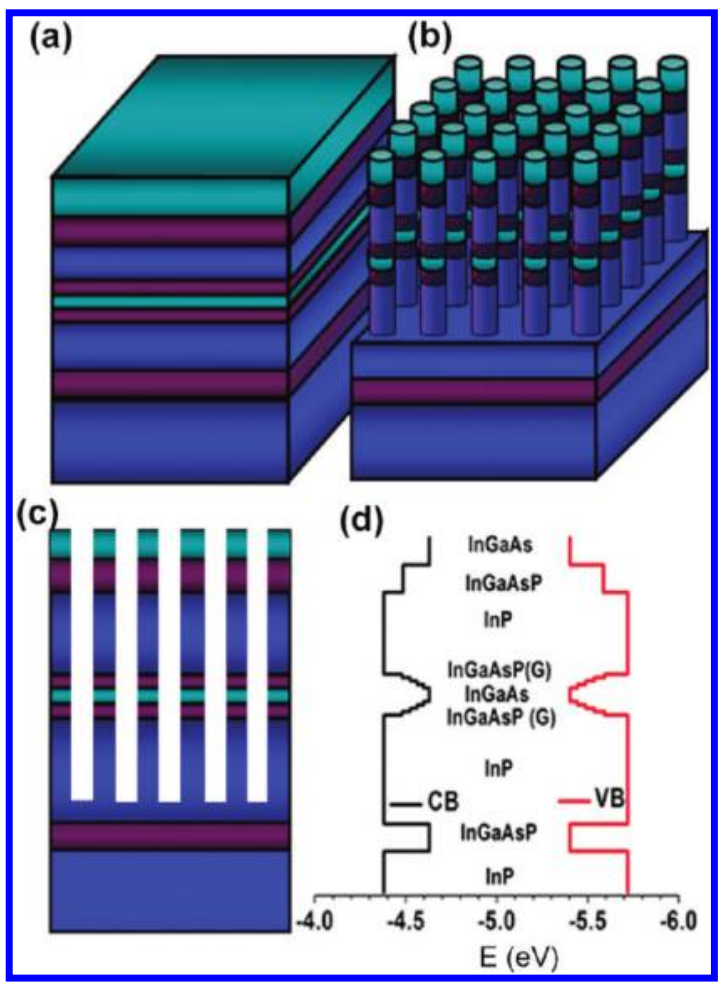

Figure 3. Schematic of heterostructure wafer and nanowires. (a) Schematic of heterostructure wafer on InP substrate; (b) nanowire array after etching; (c) 2D view of the heterostructure nanowire array; (d) corresponding band-edge profiles of conduction (CB) and valence band (VB) across the layers (along the wire axis direction after etching). The InGaAsP (G) layers represent stepwise composition graded layers with a thickness of $20 \mathrm{~nm}$ each with $P$ composition increasing from 13 to $60 \%$ starting from InGaAs layer of $20 \mathrm{~nm}$ thick to both sides.

were observed when InP substrates were etched by chlorine $\left(\mathrm{Cl}_{2}\right)$-based gas mixtures, due to the "micromask" effect from indium chloride, a low-volatility reaction product. ${ }^{24}$ In contrast, there is no low-volatility reaction product formed during $\operatorname{InP}$ etching with $\mathrm{CH}_{4} / \mathrm{H}_{2}$ gas mixture as used in this study. ${ }^{25}$ To investigate the formation mechanism of the nanowires, etched InP nanowires were analyzed using SEM EDX, as shown in Figure 2. EDX peaks of carbon $(\mathrm{C})$, oxygen $(\mathrm{O})$, phosphorus $(\mathrm{P})$, and indium $(\mathrm{In})$ were detected from the top ends of the nanowires. Element mapping illustrated that oxygen and carbon were rich on the top ends of nanowires, while In and P signals were seen uniformly distributed on the whole area due to the contribution from the substrate. Furthermore, during our experiments some flakes containing elements In and C were obtained (see Supporting Information Figure S1), which indicates that the flakes were possibly indium organometallic species, such as $\mathrm{InCH}_{3}{ }^{+}$, $\mathrm{HInCH}_{3}{ }^{+}$, and $\operatorname{In}\left(\mathrm{CH}_{3}\right)_{2}{ }^{+25}$ Such indium organometallic particles settle and congregate onto the substrate under certain conditions and serve as nanomasks for the subsequent nanowire formation (see Supporting Information). Thus the redeposition of reaction-product particles is a plausible mechanism for the self-masking effect.

To demonstrate the real potential of this approach, we use a similar process to produce wires with much more complex longitudinal structures. The epitaxial heterostructure with 16 custom-designed layers was grown on $\operatorname{InP}(100)$ substrate with doping profile across many layers and a middle layer structure of

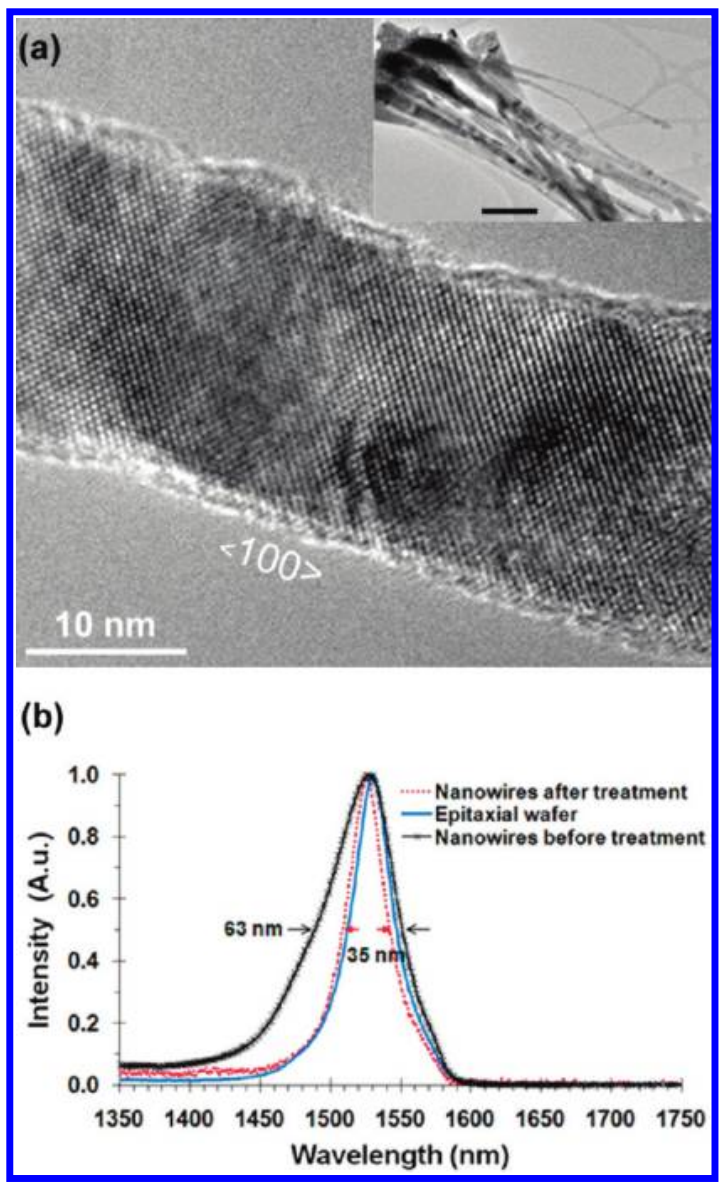

Figure 4. TEM images and PL spectra of heterostructure nanowires.(a) High-resolution electron microscopy of a nanowire; inset is a lowmagnification TEM micrograph of nanowires dispersed on $\mathrm{Cu}$ grid (scale bar $=200 \mathrm{~nm}$ ). The lengths of the nanowires were around $1 \mu \mathrm{m}$; (b) PL spectra at $77 \mathrm{~K}$ from the heterostructure wafer (solid line), heterostructure nanowires before (solid line with cross markers) and after (dashed line) chemical treatment.

InGaAsP(G)/InGaAs/InGaAsP(G) with composition graded quaternary layers, as shown in Figure 3a. The corresponding band edge profiles are shown in Figure 3d. Figure 3b,c shows schematic of nanowires etched from the epitaxial multilayers shown in Figure 3a.

Figure 4a shows the TEM images of the nanowires etched from the heterostructure wafer shown in Figure 3. The multilayer nanowires shown in Figure 4a were etched for 30 cycles, and the lengths of the nanowires were around $1 \mu \mathrm{m}$. The inset of Figure 4a shows a low-magnification TEM micrograph. The morphology and diameter range of the etched multilayer nanowires were almost identical with the etched InP nanowires shown in Figure 1a. Figure 4a shows single crystalline structure of the etched heterostructure nanowires. A very thin $(\sim 1 \mathrm{~nm}$ thick $)$ amorphous layer was seen on the surface of the nanowire, which otherwise appeared smooth down to atomic level.

PL measurements were performed on these nanowires at the temperature of $77 \mathrm{~K}$. The PL peak from the heterostructure wafer was very narrow with FWHM of $35 \mathrm{~nm}(19 \mathrm{meV})$ at $1.530 \mu \mathrm{m}$ originating from the InGaAs segment in the middle. The FWHM of PL peak from the heterostructure nanowires was around $63 \mathrm{~nm}$ $(33 \mathrm{meV})$, wider than that from the wafer, but was still much narrower than that from wires grown by bottom-up growth as 
mentioned in the following. The increase of PL width of nanowires compared to that of the wafer was caused by the surface damages, as indicated by the $1 \mathrm{~nm}$ amorphous surface layer (see Figure 4a). Chemical treatment was performed to remove the surface damages (see Supporting Information). After it, PL spectrum was measured and shown in Figure $4 \mathrm{~b}$ in dashed line. The fwhm of nanowire after such treatments is improved to around $35 \mathrm{~nm}(19 \mathrm{meV})$, which is almost indistinguishable from that of the wafer. In contrast, the PL width of InGaAs nanowires obtained in bottom-up approach by $\mathrm{MOCVD}^{26-28}$ or $\mathrm{MBE}^{29}$ are generally larger even at lower temperature: $15-30 \mathrm{meV}$ at $4.5 \mathrm{~K},{ }^{26}$ or $30-60 \mathrm{meV}^{28}$ at $4 \mathrm{~K}$. Even with a protecting GaAs shell, the linewidth was $87 \mathrm{meV}$ at $14 \mathrm{~K}$ for InGaAs/GaAs core-shell nanowires and much wider without the shell. ${ }^{29}$ Obviously our top-down approach, which combines etching and subsequent treatment, produces heterostructure nanowires with superior surface quality compared to nanowires (even without any longitudinal structures) produced by bottom-up approaches.

In summary, we have demonstrated a simple but powerful approach of fabricating vertical array of $\mathrm{InP}$ nanowires and InGaAsP/InP composition-graded heterostructure nanowires using ICP-RIE with a $\mathrm{CH}_{4} / \mathrm{H}_{2}$ gas mixture. The fabrication method does not need any prefabricated hard masks by taking advantage of a nanoscale self-masking effect. The diameters of the rod-shaped nanowires were centralized from 20 to $40 \mathrm{~nm}$, resulting in very high areal density of $1.8 \times 10^{10} \mathrm{~cm}^{-2}$. PL spectra from the InP nanowires and InGaAsP/InP composition-graded heterostructure nanowires showed the narrowest linewidth ever measured for any nanowires, including those grown by bottom up approaches, such as MOCVD or MBE, indicating the highest optical quality of the etched nanowires. Possible formation mechanism of the nanowires has been discussed. Both the complexity of longitudinal structures and the line width of the $\mathrm{PL}$ set the record for nanowires in similar bandgap range, demonstrating the powerfulness of this approach. Even though RIE etching has been used for microfabrication to produce micrometer-scale optoelectronic devices for a long time, it is thought that such etching is not adequate for producing much smaller features at nanoscale with high optical quality. Our results show the feasibility of such nanofabrication. We believe that this top-down method provides an important alternative for producing high quality nanowires to the bottom-up approaches. This approach combined the best of the heterostructure wafer growth with the advanced fabrication techniques, all perfected over the last few decades, to solve one of the important challenges in nanowire fabrication. The compatibility with the standard III-V fabrication and the related scalability make this approach appealing as a large scale manufacturable way of producing nanowire-based electronic and optoelectronic devices.

\section{ASSOCIATED CONTENT}

S Supporting Information. Additional information and figures. This material is available free of charge via the Internet at http://pubs.acs.org.

\section{AUTHOR INFORMATION}

\section{Corresponding Author}

*E-mail: cning@asu.edu.

\section{ACKNOWLEDGMENT}

This work was supported by the DARPA NACHOS Program and by the Army Research Office (ARO).

\section{REFERENCES}

(1) Yang, P.; Lieber, C. M. Science 1996, 273, 1836-1840.

(2) Wu, Y.; Yang, P. J. Am. Chem. Soc. 2001, 123, 3165-3166.

(3) Björk, M. T.; Ohlsson, B. J.; Sass, T.; Persson, A. I.; Thelander, C.; Magnusson, M. H.; Deppert, K.; Wallenberg, L. R.; Samuelson, L. Appl. Phys. Lett. 2002, 80, 1058-1060.

(4) Lu, W.; Lieber, C. M. Nat. Mater. 2007, 6, 841-850.

(5) Dick, K. A.; Deppert, K.; Larsson, M. W.; Martensson, T.; Seifert, W.; Wallenberg, L. R.; Samuelson, L. Nat. Mater. 2004, 3, 380-384.

(6) Yan, R.; Gargas, D.; Yang, P. D. Nat. Photonics 2009, 3, 569-576.

(7) Qian, F.; Li., Y.; Gradecak, S.; Park, H.; Dong, Y.; Ding, Y.; Wang, Z. L.; Lieber, C. M. Nat. Mater. 2008, 7, 701-706.

(8) Wang, Z. L.; Song, J. H. Science 2006, 312, 242-312.

(9) Thurn-Albrecht, T.; Schotter, J.; Kastle, G. A.; Emley, N.; Shibauchi, T.; Krusin-Elbaum, L.; Guarini, K.; Black, C. T.; Tuominen, M. T.; Russell, T. P. Science 2000, 290, 2126-2129.

(10) Novotny, C. J.; Yu, E. T.; Yu, P. K. L. Nano Lett. 2008, $8,775-779$.

(11) Garnett, E. C.; Yang, P. J. Am. Chem. Soc. 2008, 130, 9224-9225.

(12) Ning, C. Z. Phys. Status Solidi B 2010, 247, 774-788.

(13) Jabeen, F.; Rubini, S.; Martelli, F. Microelectron. J. 2009, 40, 442-445.

(14) Gudiksen, M. S.; Lauhon, L. J.; Wang, J.; Smith, D. C.; Lieber, C. M. Nature 2001, 415, 617-620.

(15) Lauhon, L. J.; Gudiksen, M. S.; Lieber, C. M. Philos. Trans. R. Soc. London, Ser. A 2004, 362, 1247-1260.

(16) Dick, K. A.; Kodambaka, S.; Reuter, M. C.; Deppert, K.; Samuelson, L.; Seifert, W.; Wallenberg, L. R.; Ross, F. M. Nano Lett. 2007, 7, 1817-1822.

(17) Paladugu, M.; Zou, J.; Guo, Y. N.; Zhang, X.; Joyce, H. J.; Gao, Q.; Tan, H. H.; Jagadish, C. Appl. Phys. Lett. 2008, 93, No. 101911.

(18) Krogstrup, P.; Yamasaki, J.; Sorensen, C. B.; Johnson, E; Wagner, J. B.; Pennington, T.; Aagesen, M.; Tanaka, N.; Nygard, J. Nano Lett. 2009, 9, 3689-3693.

(19) Bhunia, S.; Kawamura, T.; Watanabe, Y.; Fujikawa, S.; Tokushima, K. Appl. Phys. Lett. 2003, 83, 3371-3373.

(20) Chuang, L. C.; Moewe, M.; Crankshaw, S.; Chang-Hasnain, C. Appl. Phys. Lett. 2008, 92, No. 013121.

(21) Mattila, M.; Hakkarainen, T.; Mulot, M.; Lipsanen, H. Nanotechnology 2006, 17, 1580-1583.

(22) Karouta, F.; Docter, B.; Geluk, E. J.; Sander-Jochem, M. J. H.; van der Tol, J. J. G. M.; Smit, M. K. Proc. 18th Annu. IEEE/LEOS 2005, 987-988.

(23) Tsakalakos, L.; Balch, J.; Fronheiser, J.; Korevaar, B. A.; Sulima, O.; Rand, J. Appl. Phys. Lett. 2007, 91, No. 233117.

(24) Matsutani, A.; Ohtsuki, H.; Muta, S.; Koyama, F.; Iga, K. Jpn. J. Appl. Phys. 2001, 40, 1528-1529.

(25) Melville, D. L.; Simmons, J. G.; Thompson, D. A. J. Vac. Sci. Technol., B 1993, 11, 2038-2045.

(26) Yoshimura, M.; Tomioka, K.; Hiruma, K.; Hara, S.; Motohisa, J.; Fukui, T. Jpn. J. Appl. Phys. 2010, 49, 04DH08.

(27) Kim, Y.; Joyce, H. J.; Gao, Q.; Tan, H. H.; Jagadish, C.; Paladugu, M.; Zou, J.; Suvorova, A. A. Nano Lett. 2006, 6, 599-604.

(28) Moewe, M.; Chuang, L. C.; Crankshaw, S.; Ng, K. W.; ChangHasnain, C. Optical Express 2009, 17, 7831-7836.

(29) Jabeen, F.; Rubini, S.; Grillo, V.; Felisari, L.; Martellib, F. Appl. Phys. Lett. 2008, 93, No. 083117. 